\title{
STRENGTH CHARACTERISTICS OF CHANNEL BEAMS UNDER WARPING AND TWIST PRE- VENTION
}

\author{
Shigeru KURANISHI*, Satoru SUDOU**, \\ Masatoshi NAKAZAWA*** \\ and Tetsuo IWAKUMA****
}

\begin{abstract}
The fundamental bending strength characteristics of channel section beams are studied by a numerical analysis and checked with respect to the effects of loading conditions, type of cross sections and initial imperfections. The slender type of high depth channel to be likely used in plate girder structures and the compact section type for hot-rolled shapes are adopted here. Mainly emphasized are the effects of prevention of twist at the loading point and the warping restraint at beam ends. The reduction of bending strength due to lateral-torsional buckling is significantly improved by the end warping restraint and prevention of twist at the loading point. Finally, it is concluded that the channel section beams can be used as main structural members.
\end{abstract}

Key Words : Channel section, Beam, Lateral-torsional buckling, Warping restraint, Twist prevention, FEM

\section{INTRODUCTION}

It is well-known that the gravity center of cross section of the members with monosymmetrical cross sections does not coincide with the shear center. Moreover, since the shear center does not generally locate in the cross-sectional area, it becomes almost impossible to apply the external forces to this shear center in the practical use. Therefore, torsion or warping together with bending and shear might be occurred unavoidably when monosymmetrical section members are used for beams or columns. This will result in more significant reduction of the bending strength in comparison with equivalent doublysymmetrical section members and yield the complexity in the structural analysis.

However, the shape of some of the monosymmetrical cross section, for example channel section or $\mathrm{T}$ section, is generally suitable for the connection between members using bolts and welding. By this reason, the monosymmetrical cross section is usually used as the secondary members which are not expected their full strength but for need of the easy connection.

In this paper, the bending strength of channel section beams in the state of actual usage is emphasized and possibilities of the use as main structural members is discussed considering the merit of no projection of flanges to one side of the cross section, which brings about them easy connections details and a

* Dr.Eng., Professor, Department of Civil Engineering, Tohoku University, Aoba Sendai 980, JAPAN

** M.Eng., former graduate student of Tohoku University, Nihon Koukan Co., Yokohama Kanagawa 230, JAPAN

*** Dr.Eng., Research Associate, Department of Civil Engineering, Tohoku University

**** Ph.D., Associate Professor, Department of Civil Engineering, Tohoku University good appearance.

The researches of the ultimate strength of channel members are not so much. Rasmussen and Hancock ${ }^{1}$ dealt with the problem how to eliminate the deformations of fabricated channel members caused after welded. A fabricating process by presetting and subsequently clamping of the plate elements prior to welding is presented, and a calculating procedure of the residual stresses induced by the combined effects of presetting and shrinkage after welding is outlined. Residual stresses are measured and compared with theoretical ones.

The compressive strength of slender channel columns is investigated by Rasmussen and Hancock ${ }^{2)}$. The specimens consist of different geometries of cross sections fabricated by welding and are made of high strength steels. Columns are tested concentrically and eccentrically between pinned ends, and fixed ended stub column tests are also performed. The tested results are compared with the codes of several countries. The local buckling loads are also tested and compared with theoretical ones.

Moreover, Lau and Hancock ${ }^{3)}$ carried out compression tests for various cold-formed channel sections to study the effect of distortional buckling in the inelastic range. Lipped channel sections may buckle in a distortional mode when they are subjected to compression. It is found that the inelastic buckling analysis based on a spline finite strip method gives an accurate estimate of the tested failure loads and distortional failure modes.

After that, Rasmussen and Hancock ${ }^{4}$ ) examined the result of a nonlinear analysis of thin-walled channel columns and the tested ones in detail. These columns are analyzed as beam-columns having non- 


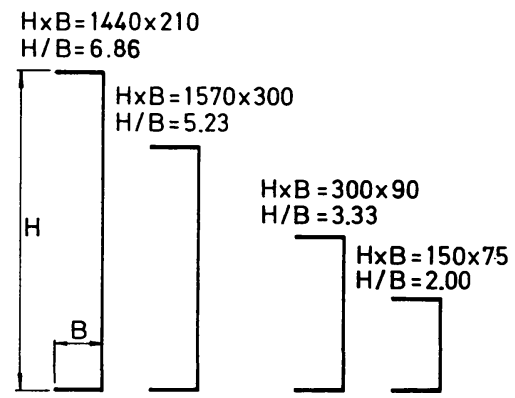

(a) slender section (b) compact section

Fig. 1 Type of channel section.

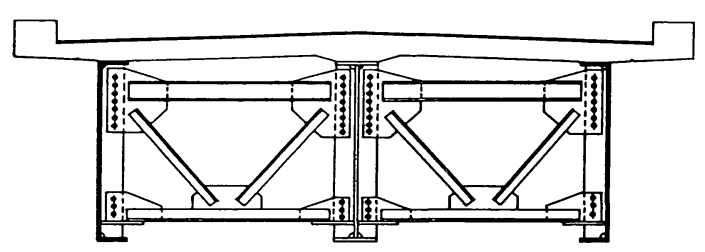

Fig. 2 Example of slender channel section used in the plate girders. linear constitutive relationships, and the effect of local buckling in flange and web plates is also included. Based on the theoretical and experimental load-shortening and load-deflection curves, it is concluded that the spatial plastic mechanism analysis employed there agrees closely with tested.

Kubota and Kuranishi ${ }^{5}$ studied the ultimate strength of the channel beams subjected to pure bending by numerical calculation. Three loading locations in the lateral direction of the cross section are considered; i.e. on the centroid, middle of web plate and shear center of the cross section. Based on the comparison of strengths with those of I section members, the modified factors to the predicting formula of the strength of I section members are suggested.

$\mathrm{Kubo}^{6)}$ carried out the experimental study of the lateral-torsional buckling strength of cold-formed steel channel beams with and without lips under a concentrated load applied on the middle of simply supported span. The vertical load is applied on the top flange in three vertical planes pass through the shear center, web and centroid of the cross section respectively.

Hasegawa et al. ${ }^{7}$ investigated the effects of load location in the vertical direction of channel beams, namely at the top flange level, shear center level and bottom flange level.

Generally speaking, researches concerned with the strength of channel members are not so extensive and fundamental knowledge is not sufficient to apply them to practical use. Hence in this paper, the fundamental strength characteristics of channel beams are checked firstly with respect to the effects of the loading conditions, type of cross sectional form and initial imperfections.

In the actual situation of usage of channel beams in the frame structures, the twist of the cross section at the loading point is probably prevented by the connected other beams or column members. For example, in the plate girder system, the main girders, even so they are channel section girder, are con- nected together with lateral beams, and the torsional deformation is restrained at the connections with the lateral beams where the external loads are applied. Considering these situation of usage in the structure systems, the effect of prevention of twist at the loading points and elastic restraints at beam ends are positively discussed. The another purpose of this study is to assure the possibility of adopting the channel members as main structural members.

\section{NUMERICAL METHOD AND CHANNEL SECTION PROP- ERTY}

\section{(1) Numerical method}

The numerical method employed here is essentially same as of Ref. 8)-11), and an incremental equilibrium equation based on the virtual work principle is adopted. Equivalent stress-strain relationships are assumed to be elastic-perfectly plastic type. The von Mises yield criterion including the axial stress, St. Venant shear stress and another shear stress due to nonuniform bending and torsion is used. Hook's law for the elastic range and the PrandtlReuss incremental equations for the inelastic range are employed.

A cross section is divided by 10 in the flange width, 20 in the web depth and 8 in the thickness direction of the flange or web plate based on the convergence study. Concerning material constants; Young modulus $E=206 \mathrm{MN} / \mathrm{m}^{2}$, shear modulus $G=79 \mathrm{MN} / \mathrm{m}^{2}$, Poisson's ratio $\nu=0.3$, tensile yield stress $\sigma_{Y}=235 \mathrm{MN} / \mathrm{m}^{2}$ are used through this analysis.

\section{(2) Configuration of channel section}

Two types of channel cross section as shown in Fig. 1 are adopted here considering the different use according to the purpose of the function. $H$ and $B$ are the web depth and flange width, respectively. The slender type of high depth channel are picked up to be likely used in plate girder structures 
Table 1 Channel section properties used in the numerical analysis.

\begin{tabular}{|c|l|l|l|l|}
\hline type & \multicolumn{2}{|c|}{ slender section } & \multicolumn{2}{c|}{ compact section } \\
\hline$H \times B$ & $1570 \times 300$ & $1444 \times 210$ & $300 \times 90$ & $150 \times 75$ \\
\hline$H(m)$ & 1.57 & 1.444 & 0.3 & 0.15 \\
$B(m)$ & 0.3 & 0.21 & 0.09 & 0.075 \\
$t_{w}(m)$ & 0.01 & 0.01 & 0.01 & 0.0065 \\
$t_{f}(m)$ & 0.025 & 0.022 & 0.016 & 0.0102 \\
$A\left(m^{2}\right)$ & $3.02 \mathrm{e}-02$ & $2.324 \mathrm{e}-02$ & $5.574 \mathrm{e}-03$ & $2.372 \mathrm{e}-03$ \\
$I_{y}\left(m^{4}\right)$ & $1.188 \mathrm{e}-02$ & $6.958 \mathrm{e}-03$ & $7.417 \mathrm{e}-05$ & $8.668 \mathrm{e}-06$ \\
$I_{z}\left(m^{4}\right)$ & $2.714 \mathrm{e}-04$ & $8.974 \mathrm{e}-05$ & $4.188 \mathrm{e}-06$ & $1.358 \mathrm{e}-06$ \\
$I_{\omega}\left(m^{6}\right)$ & $1.137 \mathrm{e}-04$ & $3.260 \mathrm{e}-05$ & $6.043 \mathrm{e}-08$ & $4.765 \mathrm{e}-09$ \\
$J\left(m^{4}\right)$ & $3.637 \mathrm{e}-06$ & $1.957 \mathrm{e}-06$ & $3.351 \mathrm{e}-07$ & $6.492 \mathrm{e}-08$ \\
$f=\frac{M_{P}}{M_{Y}}$ & 1.147 & 1.190 & 1.190 & 1.162 \\
$\frac{\pi^{2} E I_{\omega}}{G J}$ & 802.0 & 427.4 & 4.628 & 1.883 \\
\hline
\end{tabular}

Table 2 Section properties of I-girder for comparison.

\begin{tabular}{|c|l|l|}
\hline type & slender section & compact section \\
\hline$H \times B$ & $1570 \times 300$ & $300 \times 150$ \\
\hline$H(m)$ & 1.57 & 0.3 \\
$B(m)$ & 0.3 & 0.15 \\
$t_{w}(m)$ & 0.01 & 0.008 \\
$t_{f}(m)$ & 0.025 & 0.013 \\
\hline
\end{tabular}

as shown in Fig. 2, and the compact section type is one model of hot-rolled shapes. The section property of these channel sections is summarized in Table $\mathbf{1}$. $t_{w}$ and $t_{f}$ are the thickness of web plate and flange plate, respectively. $A, I_{y}, I_{z}, I_{\omega}$ and $J$ are the crosssectional area, moment of inertia with respect to $y$, $z$ axes, the warping constant and St. Venant constant, respectively. Shape factor $f$ is also tabulated in the same table. I sections usually used for the same purposes as above-mentioned are also selected for the comparison as shown in Table 2 .

\section{(3) Residual stress}

A few data from the residual stress measurements of channel section, for example, presented by Rasmussen and Hancock ${ }^{1)}$ and Nishida and Hosina ${ }^{12)}$ are available now. Considering the measured results, the residual stress distributions are assumed here as shown in Fig. 3 and represented in the following expression containing amplitude factors $K, K_{1}, K_{2}$ and $\alpha$ :

for welded type:

$$
\begin{aligned}
& K_{1}=-\frac{X\left(t_{f}+t_{w}\right)+K_{2}(1-2 B) t_{f}}{(X-H) t_{w}}, \\
& K_{2}=\frac{-2 X^{2}+3 X t_{w}}{-3 X t_{w}-6 B^{2}+2 X^{2}+9 B t_{w}},
\end{aligned}
$$

for hot-rolled type:

$$
\alpha=\frac{(1-K) H t_{w}+2 B t_{f}}{2 B K t_{f}},
$$

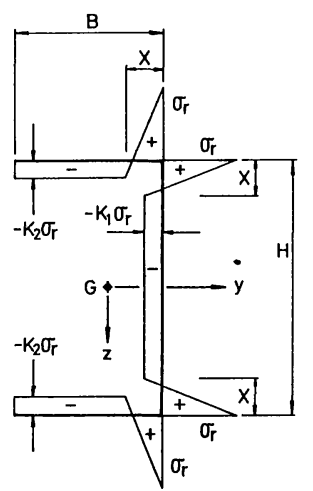

(a) welded type

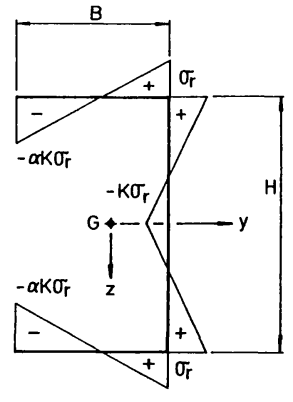

(b) hot-rolled type
Fig. 3 Residual stress distribution.

$$
K=1-\frac{4 B^{2} t_{f}}{\left(-4 B+3 t_{w}\right) H t_{w}},
$$

where self-equilibrium conditions are satisfied in these manner,

$$
\begin{gathered}
\int_{A} \sigma_{r} d A=0 \\
\int_{A} \sigma_{r} y d A=0 \\
\int_{A} \sigma_{r} z d A=0 \\
\int_{A} \sigma_{r} \omega d A=0 .
\end{gathered}
$$

where $X$ in Fig. 3 is fixed to be $0.035 m$ for all specimens, based on the experimental observation by Kondo et al. ${ }^{13)}$ of that the range of tensile residual stress is not depend on the flange width if thickness is constant.

\section{NUMERICAL RESULTS}

\section{(1) Comparison of numerical and experi- mental results}

In order to confirm the validity of the numerical method and to obtain the fundamental properties of channel members, we compared the lateral-torsional buckling strengths calculated by using the same proportions and material properties as those in the experiments by $\mathrm{Kubo}^{6}$ ). A simply supported beam subjected to a concentrated load at the mid-span is analyzed at first. Warping at both ends are set free.

The mode of initial deflection is assumed to be half sinusoidal shape in the analysis, but its maximum amplitude and the pattern of the distribution of residual stresses are set the same as those of the experimental specimens above-mentioned. Fig. 4 shows the comparison of the numerically calculated 


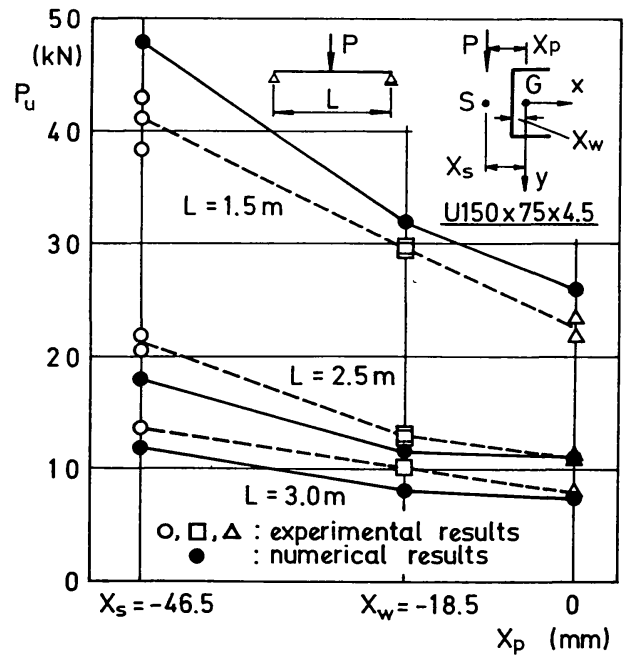

Fig. 4 Comparison of lateral-torsional strength between numerical analysis and experimental results.

lateral-torsional buckling strength and the experimental ones. The abscissa shows the eccentricities of the loading points from the gravity center of cross section. Although, in some cases, the difference between the calculated and experimental ones is existing, but almost the same tendencies are observed. This may suggest the validity of the numerical analysis considering the difficulty to simulate the material properties of cold-formed shapes.

(2) Ultimate strength characteristics of channel members under pure bending

Fig. 5 shows the lateral-torsional buckling strength curve of a simply supported beam without initial imperfections under pure bending for a plate girder type and hot-rolled type of channel sections, respectively. Two end conditions, namely free warping and restrained warping are adopted for comparison. In addition to them, simply supported double symmetrical I beam with free warping at the ends is also analyzed and illustrated in the figures for comparison. Pure bending moment at the both ends are applied in the plane including the shear center, and the ultimate bending strength $M_{U}$ is normalized by full plastic moment $M_{P}$. The slenderness parameter $\bar{\lambda}^{14) 15)}$ of the abscissa is defined by

$$
\bar{\lambda} \equiv \sqrt{\frac{M_{P}}{M_{E}}},
$$

where $M_{E}$ is the elastic lateral-torsional buckling moment given by

$$
M_{E}=\frac{\pi}{L} \sqrt{\frac{1}{\gamma} E I_{z} G J\left(1+\frac{\pi^{2} E I_{\omega}}{G J L^{2}}\right)} .
$$
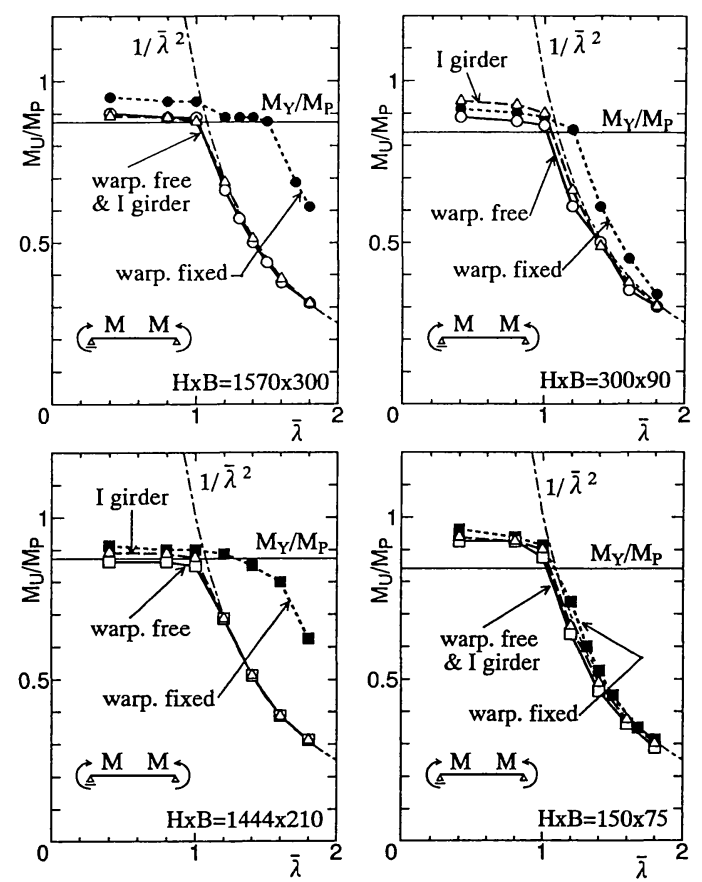

Fig. 5 Ultimate strength of a simply supported channel beam.

$\gamma$ is a factor to express the effect of in-plane curvature given by

$$
\gamma \equiv 1-\frac{I_{z}}{I_{y}}
$$

and $L$ is the length of channel beam.

The simply supported channel beams have almost the same ultimate strength as I-beam in the range of $\bar{\lambda}>1.2$ and can be approximated by the Euler curve expressed by $1 / \bar{\lambda}^{2}$. However, in the range of $0.4<\bar{\lambda}<1.2$, the curves differ from those for Ibeams and inelastic lateral-torsional buckling occurs in some different manner, but these can be presented conservatively by the yield moment $M_{Y}$.

On the other hand, the beams with warping restraint at the ends shows always higher bending strength than the case of free warping in the range of $\bar{\lambda}>1.2$. Especially, the increase of strength of the plate girder type due to the warping restraint at the ends is remarkable in comparison with the case of hot-rolled type sections. This may be explained by the difference of their torsional property. Galambos ${ }^{16)}$ presented the predicting formula for the elastic lateral-torsional buckling strength of monosymmetric members as follows:

$$
M_{c r}=\frac{\pi}{K_{y} L} \sqrt{E I_{y} G J\left[1+\frac{\pi^{2} E I_{\omega}}{G J\left(K_{z} L\right)^{2}}\right]},
$$




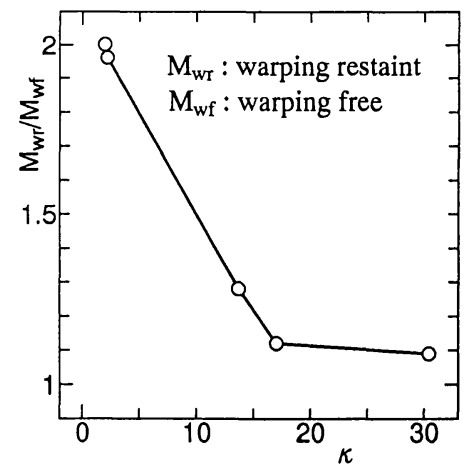

Fig. 6 Relation between rigidity ratio $\kappa$ and bending strength.

where $K_{y}, K_{z}$ are the effective length factors with respect to the $y$ and $z$ direction including the effect of end conditions. If warping at the ends is free, $K_{z}$ equals unity. The warping restraint decreases the value of $K_{z}$ to result in larger buckling moment $M_{c r}$ as well-known in Eq. 7. Hence, the effect of warping restraint on lateral-torsional buckling is affected by the rigidity ratio $E I_{\omega} / G J$ of warping and torsional rigidity. Thus, we define the torsional rigidity ratio $\kappa^{17)}$ as given by

$$
\kappa \equiv L \sqrt{\frac{G J}{E I_{\omega}}} \text {. }
$$

Fig. 6 shows the relationship between the torsional rigidity ratio $\kappa$ and the reduction factor of bending capacity due to the warping restraint. This factor is expressed by the ratio of $M_{w r} / M_{w f}$, where $M_{w r}$ and $M_{w f}$ are the bending strength under warping restraint and warping free conditions, respectively.

When the value of $\kappa$ decreases, significant increase of the ratio $M_{w r} / M_{w f}$ is recognized in Fig. 6. Note that the plate girder section has smaller ratio $\kappa$ than the hot-rolled type. Therefore, this results in the greater increase of ultimate bending strength in the channel member of plate girder section.

\section{(3) Effect of initial imperfections}

The effect of the initial deflections in the lateral direction and residual stresses on the strength of channel beams is investigated under warping free and restrained end conditions. The residual stress distribution patterns assumed here are the welded type for the plate girder type of channel section and the hot-rolled type for shape type. The shape of initial deflections is assumed to be sinusoidal half wave, and its magnitude at the mid-span is varied from $1 / 1000$ to $-1 / 1000$ of the span length $L$. The results are represented by the beam strength curve in Figs. 6 and 7 and compared with the case of no initial imperfection.
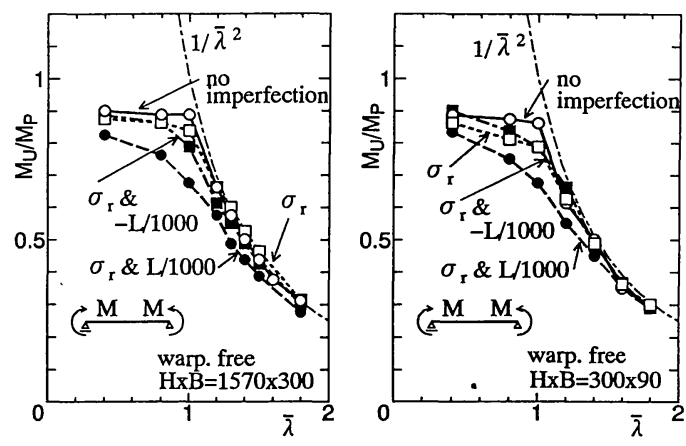

Fig. 7 Influence of initial imperfections; warping free condition.
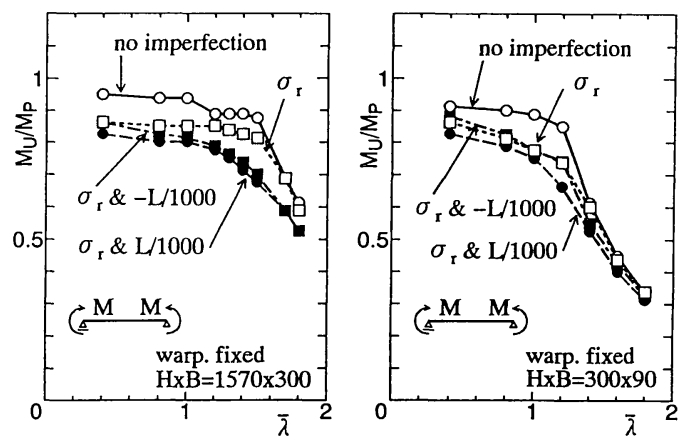

Fig. 8 Influence of initial imperfections; warping restricted condition.

\section{a) Warping free condition}

The tendency of the beam strength curves is similar to each other for the four sections analyzed here and the difference of sectional proportion has less effect on the beam strength under the warping free end conditions. In the range of $\bar{\lambda}>1.2$ in Fig. 7, the effect of the residual stresses on the beam strength is not recognized. This is because that, in this case, the plastification occurs in the quite limited portion of beams and the collapse is governed mainly by the elastic lateral-torsional buckling.

The effect of initial deflections is more interesting. The smallest strength is obtained in the case of $L / 1000$ in the outer direction (in the positive $\mathrm{y}$ direction in Fig. 3) among all the cases. This is explained by the coupling effect of induced stress by the initial deflection and residual stresses. If the lateral displacement by the applied moment occurs to the same direction as the initial deflection, these induced stresses and the residual stresses work for the early plastification and decreases the beam strength. Therefore, in the middle range of $\bar{\lambda}$, namely from 0.8 

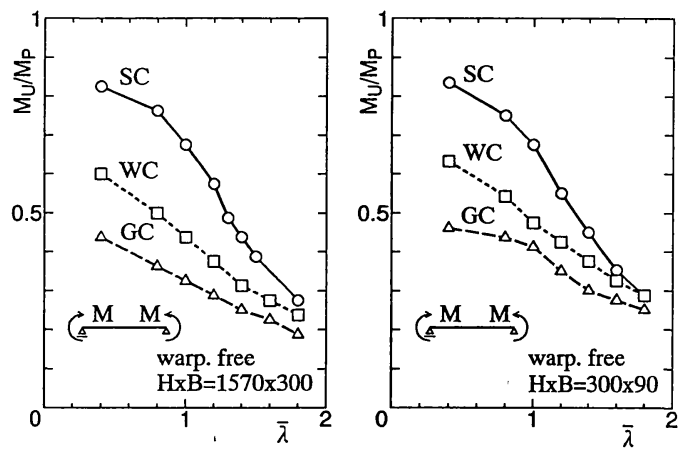

Fig. 9 Influence of location of loading points; warping free condition.
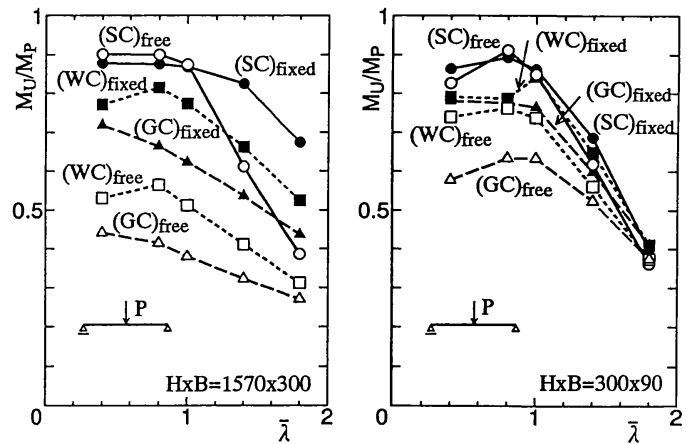

Fig. 10 Influence of location of loading points; under concentrated load at mid-span. to 1.2 , the direction of the initial deflection significantly affects the strength of channel beams.

\section{b) Warping restrained condition}

As mentioned above, in this case, the difference of the ratio $\kappa$; i.e. the difference of the sectional proportion, greatly affects the strength of channel beams. The plate girder type of channel beam can have the relatively high ultimate strength even beyond $\bar{\lambda}>1.0$. While hot-rolled type of channel section shows the gradual drop of the strength as the slenderness parameter becoming higher as shown in Fig. 8.

The introduction of the initial deflection and residual stresses yields the decrease of the ultimate strength. But there is some difference in the manner of the decrement of the strength between the plate girder type and hot-rolled type. The former can keep the strength to rather higher slenderness parameter, while the latter is not affected by the warping restraint at the ends and shows similar strength curves as those of the warping free ones. In both cases, the effect of the direction of the initial deflections is not significant. But, the smallest strength is always obtained for the initial deflection of $L / 1000$ in the warping restrained case as well as in the case of simply supported end conditions.

\section{(4) Influence of location of moment-applica- tion points}

Depending on the moment-application point, the channel beams show the different behavior and strength characteristics. Reference loading points are kept at the shear center(SC), web center(WC) and gravity center(GC), respectively, during the deformation. The effect of loading point of the applied moments is summarized in Fig. 9 in the case of warping free. The initial deflection of $L / 1000$ is included here through all the cases. As the distance of moment-application point from the shear center becomes larger, the bending strength of channel beams reduces significantly as well-known. The reduction of the strength becomes smaller in the higher range of $\bar{\lambda}$ because the strength of channel members is governed by elastic buckling.

In the warping restrained condition, it is anticipated that the plastification of the channel section yiels the difference of bending strength among three moment-application points. Although numerical results are not shown here, it must be noted that the strength of the warping restrained channel beams shows almost the same as that of the case of SC loading.

The bending strength curves of a channel beam subjected to a concentrated load at mid-span are shown in Fig. 10. The difference comes from only the effect of the torsional-warping stress in the pure bending and a concentrated load at the mid-span. The prevention of warping at both ends is also effective in these loading conditions. In the range of smaller slenderness parameter, it is recognized that the relatively lower bending strength is obtained in some cases. This is due to the early development of plastification in channel sections caused by the co-existing torsion or warping and bending.

\section{DISCUSSION ON THE EF- FECT OF TWIST AND/OR WARPING PREVENTION}

\section{(1) Twist prevention at loading points}

Suppose the practical usage of the channel members as the main girders of plate girder structures, for example, the main girders are usually connected with the cross beams. Therefore, this connections will prevent the twist and warping at that positions and increase the strength of the girders. If so, there may be no problem to use the channel members as the main structural members. Consequently, it is quite important to know the strength characteristics of channel members considering the boundary con- 

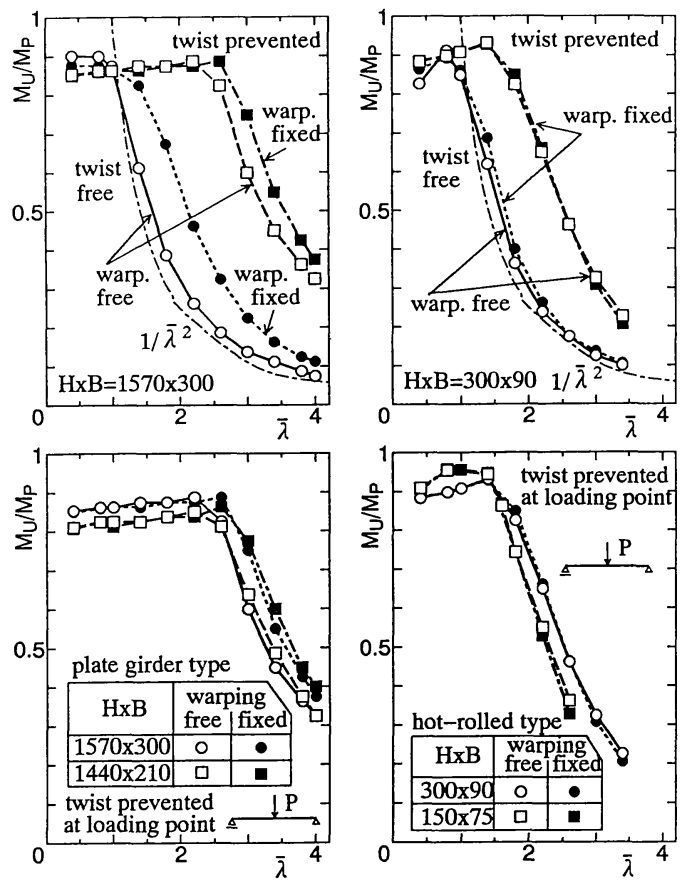

Fig. 11 Bending strength under twist prevention at loading points.

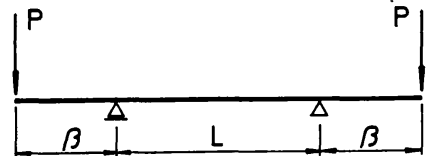

extreme outer ends

warping restrained

Fig. 12 Three-span model to evaluate the effect of elastic restraint of warping.

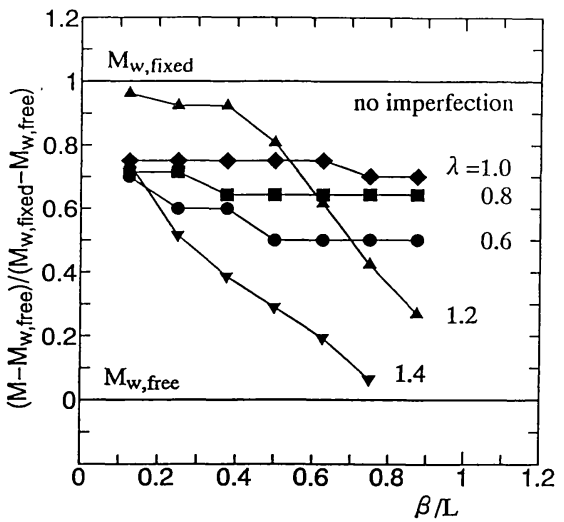

Fig. 13 Relation between bending strength and extent of warping restraint. ditions reflecting the actual connection and to what extent of the restraint can be expected.

Fig. 11 shows the bending strength curves of a channel beam subjected to a concentrated load at mid-span. Only the twist of the cross section at the loading point is strictly prevented. For this case, warping free and warping fixed end conditions are analyzed. The initial imperfections similar to the previous analysis of subsection 3.(3) are also introduced here. In the same figures, curves for twist free condition at the loading point are also plotted for comparison.

As expected above, the reduction of bending strength due to lateral-torsional buckling is significantly improved by the prevention of twist, especially in the range of $\bar{\lambda}>1.0$. Moreover, as a matter of fact, the prevention of twist at loading point brings about almost the same strength as that of the shear center loading. Actually, the twist of channel beams occurs at unrestrained portions, namely at the quarter point of span, by the initial deflections. However, its effect on the beam strength are negligibly small, and high strength can be expected to $\bar{\lambda}>2.0$, to $\bar{\lambda}>1.0$ if considered in the half span. If the twist of the cross section at the point of concentrated load is prevented, the strength requirement as the main structural members will be fully satisfied to equal to the double-symmetric section members. Thus, we can use the same design formula as for the lateral-torsional buckling strength of the beams of double symmetrical cross sections with a little modification if necessary.

\section{(2) Elastic restraint of warping at ends}

The actual end condition of channel beams should be, in some cases, elastically restrained one, namely between warping perfectly restrained and free warping. This extent of restraint greatly affects the strength of channel members.

In order to simulate the elastic restraint of warping, a three-span analytical model under constant bending moment as shown in Fig. 12 is adopted.

The outer ends of the side cantilever span are restrained in warping, and the concentrated load $\mathrm{P}$ is applied at SC position. The other displacements are kept free at these ends. At the intermediate supports, three trancendental displacements and torsion are restrained except for one longitudinal displacement due to the roller support condition. Warping is free in these intermediate supports. The beams are continuous on the intermediate supports, namely warping is elastically restrained.

The extent of warping restraint is adjusted by the side-span length of beams expressed by $\beta$, and the smaller $\beta$ gives the cross sections severe restraint. 
A typical channel section of $H \times B=1570 \times 300$ of plate girder type are analyzed, of which slenderness parameter is $0.6<\bar{\lambda}<1.4$.

Fig. 13 shows the relationships between the extent of warping restraint presented by $\beta / L$ and bending strength. In this case, any initial imperfection does not considered for the sake of simplicity. As shown in the figure, their relationships can be classified into two groups. They can be expressed by almost constant lines for $\bar{\lambda} \leq 1.0$ and almost linear one for $\bar{\lambda}>1.0$ between the case of perfectly warping restrained and warping free. Therefore, it becomes quite important to know the actual extent of the warping restraint at beam ends for use of channel members, which affects directly the ultimate strength of channel members.

\section{CONCLUSION}

In this paper, the fundamental ultimate strength characteristics of beams with two type of channel cross sections; i.e. plate girder type and hot-rolled type are investigated by FEM. The concluding remarks obtained by the numerical results and discussions are as follows:

(1) The ultimate strength of simply supported channel beams under pure bending is almost equal to those of I-beam in the range of slenderness parameter $\bar{\lambda}>1.2$ and can be approximated by the elastic lateral-torsional buckling curve of $1 / \bar{\lambda}^{2}$, in the case where loads are applied on the shear center. However, in the range of $0.4<\bar{\lambda}<1.2$, inelastic lateraltorsional buckling occurs and the strength can be presented conservatively by the yield moment $M_{Y}$.

(2) Beams with end warping restraint shows quite higher bending strength than the case of free warping. Especially, increase of the strength due to the end warping restraint is significant as for the plate girder type of channel cross section than the hotrolled type one. In other words, the channel section of plate girder type can be expected the increase of ultimate bending strength not only by the shear center loading, but also by the warping restraint.

(3) The direction of initial deflection affects significantly the strength of channel beams. As the beams deflect initially to the outer-side of the web plate, the strength becomes smaller. When the lateral displacement due to the initial outer deflection occurs towards the same direction as the initial deflection, the induced stresses are enlarged by the residual stresses, and the earlier plastification decreases the bending strength.

(4) The prevention of twist at the loading point increases the bending strength of channel members. The reduction of bending strength due to lateraltorsional buckling is significantly improved by the prevention of twist, especially in the range of $\bar{\lambda}>$
1.0. The restraint of warping and twist at loading point brings about almost the same strength as that of the shear center loading. In those cases, the strength requirement as the main structural members will be fully satisfied in the same level of that of the double-symmetric section members.

(5) The end condition of actual channel beams in a structural system is in the elastically restrained state, namely between warping fixed and warping free. This extent is estimated here by the equivalent span length connected at the both ends of the critical beam. Their relationships can be classified into two groups; almost constant lines for $\bar{\lambda} \leq 1.0$ and almost linear one for $\bar{\lambda}>1.0$ between the two ideal warping conditions according with the extent of the restraint. Therefore, it becomes quite important to understand the actual extent of warping restraint at the beam ends in the channel design.

\section{ACKNOWLEDGMENT}

This study was partially supported by Grant-inAid for Scientific Research(B ${ }^{19)}$ by The Ministry of Education, Science and Culture in 1989-1991.

\section{REFERENCES}

1) Rasmussen, K.J.R. and Hancock, G.J. : Deformations and residual stresses induced in channel section columns by presetting and welding, Research Report No.R550, The University of Sydney, School of Civil and Mining Engineering, 1987.

2) Rasmussen, K.J.R. and Hancock, G.J. : Compression tests of welded channel section columns, Research Report No.R566, The University of Sydney, School of Civil and Mining Engineering, 1988.

3) Lau, S.C.W. and Hancock, G.J. : Inelastic buckling of channel columns in the distortional mode, Research Report No.R578, The University of Sydney, School of Civil and Mining Engineering, 1988.

4) Rasmussen, K.J.R. and Hancock, G.J. : Nonlinear analysis of thin-walled channel section columns, Research Report No.R610, The University of Sydney, School of Civil and Mining Engineering, Centre for Advanced Structural Engineering, 1990.

5) Kubota, K. and Kuranishi, S. : Strength characteristics of channel beam sections, Proc. of the 40th annual conference of JSCE, 1, pp.121-122, 1985 (in Japanese).

6) Kubo, M. : Experimental study on lateral-torsional strength of cold-formed steel channel beams, Journal of Structural Engineering, JSCE, Vol.32A, pp.431-441, 1986 (in Japanese).

7) Hasegawa, A., Naveed, A. and Dellelegne, T. : Effects of load point location on the instability and nonlinear behavior of I, channel, and zee shaped beams, Structural Eng. /Earthquake Eng., JSCE, Vol.6, No.1, pp.59s-68s, 1989.

8) Sakimoto, T., Yamao, T., Kikuchi, R. and Sakata, T. : Nonlinear analysis of thin-walled frames and members with arbitrary open cross section, Journal of Structural Eng. /Earthquake Eng., JSCE, Vol.2, No.2, pp.385s-393s, 1985. 
9) Sakimoto, T., Yamao, T., Kikuchi, R. and Sakata, T. : Nonlinear analysis of thin-walled frames and members with arbitrary open cross sections, Journal of Structural Engineering, JSCE, Vol.32A, pp.255-264, 1986 (in Japanese).

10) Maalla, K. : Spatial ultimate load analysis of thinwalled members and its application to the design of channel members, Thesis presented to Tohoku University in 1988, in partial fulfillment of the requirements for the degree of doctor of Engineering.

11) Maalla, K., Iwakuma, T., Kuranishi, S. and Fukasawa, S. : A simplified spatial ultimate load analysis of members with open cross section, Structural Eng. /Earthquake Eng., JSCE, Vol.6, No.1, pp.79s-87s, 1989.

12) Nishida, S. and Hosina, H. : The estimation of residual stresses and its self equilibrium conditions in welded thin-walled members, Proc. JSCE, No.340, pp.209-212, 1983 (in Japanese).

13) Kondo, A., Hiura, T. and Kikuchi, Y. : A study on the estimation of residual stresses in welded Isections, Proc. JSCE, No.288, pp.1-11, 1979 (in Japanese).
14) Kubo, M., and Fukumoto, Y. : Effects of moment distribution on lateral-torsional buckling strength of rolled steel I-beams, Proc. JSCE, No.368, pp.255-263, 1986 (in Japanese).

15) Edited by Fukumoto, Y. : Guidelines for Stability Design of Steel Structures, Subcommittee on Stability Design Committee on Steel Structures, JSCE, pp.124-130, 1987 (in Japanese).

16) Galambos, T.V.: Structural Members and Frames, Prentice-Hall, 1968.

17) Japan Road Association : Specification for Design of Highway Bridges, Part 2, Steel Bridges, 1990 (in Japanese).

18) Nishino, F. and Hasegawa, A. : Elastic Analysis of Structures, Gihodo, 1983 (in Japanese).

19) Kuranishi, S. : Strength and design of thin-walled members with non-symmetric open section, Finat Report of Grant-in-Aid for Scientific Research (B), No.63460150, supported by The Ministry of Education, Science and Culture, 1991.

(Received August 12. 1991)

\section{そり拘束およびねじり拘束を受けるみぞ形鋼はりの強度特性}

倉西 茂·須藤 聡·中沢 正利・岩熊 哲夫 みぞ形断面はり部材の基本的な曲げ強度特性が数値解析によって調べられ，荷重条件， みぞ形断面形状，および初期不整の影響が検討されている.プレートガーダーに用いら れる様なスレンダーな断面および圧延形鋼のコンパクト断面が想定されている. 荷重載 荷点でのねじり拘束およびはり端部でのそり拘束の効果に特に着目しており，みぞ形鋼 はりの横倒れ座屈による曲げ强度の低下は著しく改善され，みぞ形鋼を主要部材として 用いることのできることが判明した。 